\title{
Virtues for Real-World Utilitarians
}

\section{Stefan Schubert and Lucius Caviola}

\author{
December 2021
}

Draft of chapter to be published in Issues in Experimental Moral Philosophy (Routledge).

Stefan Schubert, The Centre for Philosophy of Natural and Social Science, London School of Economics and Political Science. s.schubert@lse.ac.uk

Lucius Caviola, Dept. of Psychology, Harvard University. Icaviola@fas.harvard.edu 
Abstract: Utilitarianism says that we should maximize aggregate well-being, impartially considered. But utilitarians that try to apply this principle will encounter many psychological obstacles, ranging from selfishness to moral biases to limits to epistemic and instrumental rationality. In this chapter, we argue that utilitarians should cultivate a number of virtues that allow them to overcome the most important of these obstacles. We select virtues based on two criteria. First, the virtues should be impactful: they should greatly increase your impact (according to utilitarian standards), if you acquire them. Second, the virtues should be acquirable: they should be psychologically realistic to acquire. Using these criteria, we argue that utilitarians should prioritize six virtues: moderate altruism, moral expansiveness, effectiveness-focus, truth-seeking, collaborativeness, and determination. Finally, we discuss how our suggested list of virtues compares with common conceptions of utilitarianism, as well as with common sense morality. 


\section{Introduction $^{1}$}

Utilitarianism says that we should maximize aggregate well-being, impartially considered. But what does that mean in practice? What should someone who wants to live a utilitarian life actually do?

Utilitarians who want to apply their creed will encounter many psychological obstacles. Humans are selfish, meaning that we are disinclined to be impartial between ourselves and others. We are partial in favor of people who are close to us, which takes us further still from utilitarian impartiality. And we are scope-insensitive, meaning that our emotions do not guide us toward the problems where we can make the greatest difference. The list goes on.

All these psychological obstacles mean that it is difficult to actually live and act in accordance with utilitarianism, even for those who agree with it in the abstract. Many present and historical utilitarians have arguably failed to do so. They have not overcome these psychological obstacles, and so have not actually practiced utilitarianism particularly well in real life.

How can utilitarians best solve this problem? How can they overcome the psychological obstacles to (acting in accordance with) utilitarianism? ${ }^{2}$ We suggest that they should cultivate virtues or character traits that allow them to overcome key obstacles (cf. Crisp, 1992, 2018, Schmidt, 2017).

But there are very many psychological obstacles to utilitarianism, and people only have so much time and will-power. That means that they have to choose wisely, and prioritize the virtues that are most important. People simply do not have the psychological resources to overcome all of them. Just like utilitarians need to prioritize between what charities to donate to (cf. Peter Singer, 2015), so they need to prioritize between potential virtues. ${ }^{3}$

We suggest that utilitarians should choose virtues based on two criteria. First, they should choose impactful virtues: virtues that, once acquired, greatly increase their positive impact, as measured by utilitarian standards. In other words, virtues that potentially could confer substantial social benefits. Second, they should choose acquirable virtues: virtues that people can realistically cultivate- that are not impossibly demanding. ${ }^{4}$

\footnotetext{
${ }^{1}$ We would like to thank David Althaus, Jonathan Baron, Max Bazerman, Richard Yetter Chappell, Joshua Greene, John Halstead, Joshua Lewis, David Moss, Philipp Schönegger, Peter Singer, Pablo Stafforini, and an anonymous reviewer for their helpful comments.

${ }^{2}$ For ease of expression we will talk in terms of obstacles to utilitarianism, rather than obstacles to acting in accordance with utilitarianism.

${ }^{3}$ Our approach in this chapter is thus in line with ethical actualism - the view that what one ought to do is determined by what one will actually do, rather than by what one could possibly do (as ethical possibilism would have it) (Cohen, 2019). For instance, the virtue of extreme altruism (see below) would probably have good consequences if it was applied consistently and if it did not affect the extent to which utilitarians display the other virtues. But actually, it would probably not be applied consistently, and would probably affect the other virtues adversely. That is why we do not recommend it. Similarly, our approach should be seen as prescriptive (it is about what we should do, given our limitations) rather than normative (what we should ideally do, absent any limitations) (see Baron, 1994, 2000).

${ }^{4}$ These two criteria are inspired by a similar framework that effective altruists use to identify high-impact causes (e.g., global poverty and animal welfare). Effective altruists have argued that the highest-impact problems are those that are important (or large in scale), tractable (or solvable), and neglected (MacAskill, 2015). Our two criteria are akin to the first two of these criteria.
} 
To identify virtues, and to assess how impactful and acquirable they are, we draw on lessons from the effective altruism community. The effective altruism community is a global community of people who use their time and money to try to maximize their social impact, using evidence and reasoning. While effective altruism and utilitarianism are not identical, utilitarianism entails effective altruism: if you are utilitarian, then you arguably ought to be an effective altruist (de Lazari-Radek and Singer, 2017). (Though the converse does not hold.) In line with that, a majority of effective altruists are in fact utilitarians (70\% in the latest Effective Altruism Survey; Rethink Priorities 2019). Therefore, it is only natural to look at what virtues and norms the effective altruism community promotes as part of their work to do good effectively.

How impactful a virtue is largely depends on facts of the world. For instance, as we will see, a key reason why effectiveness-focus is such an impactful virtue is that the most effective charities are at least a hundred times more effective than the average charity (Caviola et. al., 2020a, Ord, 2019, Jamison et al. 2006). Acquirability, on the other hand, is a psychological matter. To assess acquirability, we draw on research on the psychology of utilitarianism and other relevant psychological research. For instance, we look at the prevalence of the candidate virtues. If a virtue is extremely rare, it is likely not particularly acquirable. But if a virtue is more common, at least in specific groups-such as the effective altruism community - then it is at least possible that it may be relatively acquirable. However, we should make clear that we do not have a precise sense of how acquirable the candidate virtues are, and that we therefore have been forced to settle for broad judgments. Future research may shed more light on this question.

We suggest six utilitarian virtues that we find especially important. First, moderate altruism: to partly overcome selfishness and sacrifice some resources for others. Second, moral expansiveness: to overcome our natural partiality against distant beneficiaries. Third, effectiveness-focus: to overcome our emotional numbness to the scale of a problem, and our biases toward ineffective ways of helping. Fourth, truth-seeking: to overcome motivated reasoning and a host of epistemic biases in order to find the most effective ways of maximizing well-being. Fifth, collaborativeness: to engage in fruitful collaboration with other utilitarians, and to be willing to compromise with moral opponents. And sixth, determination: to consistently act on utilitarian principles with persistence and deliberation. ${ }^{5}$

Importantly, this list is tentative-it should be seen as a suggestion that hopefully inspires more research. It is also dependent on context and culture - what virtues are most important depend on time and place. We have identified these virtues with a contemporary Western audience in mind, and so acknowledge that they may not be universally applicable.

Many have noticed that utilitarians need to take facts about our psychology into account when deciding what to do, including early utilitarians like John Stuart Mill (1861/1992) and Henry Sidgwick (1907/1981). More recently, Max Bazerman (2020) has argued that when we do good, we should aim for "maximum sustainable goodness" rather than a theoretical maximum (cf. also Kaplow and Shavell (2002), and Joshua Greene's (2014) notion of "deep pragmatism"). Likewise, several philosophers have argued that utilitarians need to cultivate virtues (Mill, 1861/1992, Railton, 1984, Crisp, 1992, Driver, 2001, Bradley, 2018). We add to this debate by creating a concrete and modern list of virtues, based on insights from effective altruism and contemporary psychological research.

\footnotetext{
${ }^{5}$ It may be that adherents of other moral theories should also cultivate many or all of these virtues, but we will not focus on that issue in this chapter.
} 


\section{Moderate altruism}

Utilitarianism says that everyone's well-being is equally valuable, ceteris paribus. This means that we have no intrinsic reasons to prioritize someone's well-being over anyone else's. Importantly, that includes ourselves. We thus have no intrinsic reason to prioritize our own well-being over others'. This is generally seen as one of the most demanding aspects of utilitarianism (Scheffler, 1994, Pettit, 1997). We are naturally relatively selfish, meaning that such impartiality does not come naturally to us. To come closer to it, utilitarians must cultivate the virtue of altruism.

But how ambitious should this altruism be? At first glance, it would seem that utilitarians should give away their money until they reach the point of marginal utility, where the marginal utility of donating equals the marginal utility of spending money on yourself (Singer, 1972). Similarly, it would seem that they should give away any organs that are not strictly needed for their continued existence to strangers. But can people realistically attain that?

Casual observation and psychological studies suggest that such extreme levels of altruism are very uncommon. Only a tiny fraction of people give away organs to strangers, and studies suggest that they have special psychological characteristics that most people do not share (Crockett and Lockwood, 2018). Even fewer give away their money up until the point of marginal utility.

In fact, there are several reasons to believe that such extreme levels of altruism would be counterproductive. First, it would likely increase the risk of burnout, which would make you less productive. That would in turn reduce your utilitarian impact. Second, the notion that you need to give away everything above the point of marginal utility may make you less motivated to acquire resources. For instance, this notion de facto forces you to give away all additional resources that you earn, effectively functioning as a $100 \%$ marginal tax rate. And like taxes, it may affect your incentives. Even if you fully endorse utilitarian principles, you may not be able to suppress your selfish impulses fully over the long term. Therefore, your productivity may go down as your self-imposed "tax rate" goes up.

In light of such considerations, many utilitarian philosophers have argued that utilitarians have instrumental reasons to be somewhat partial for themselves - and to settle for a moderate level of altruism, that is easier to acquire (e.g., Sidgwick, 1907/1981, Kagan, 1989, Unger, 1996, de LazariRadek and Singer, 2013). We agree with that view. In fact, it may be even more true when we leave the individual level of analysis and move to the collective level. Partially utilitarian communities like the effective altruism community would likely struggle greatly with recruitment if they expected members to donate to the point of marginal utility. That would in turn decrease the community's impact. In line with such reasoning, effective altruists are not encouraged to give away extremely large proportions of their income. The effective altruist giving community Giving What We Can suggests that members give away $10 \%$ of pre-tax income. That is considerably higher than the US average of 2\% (Giving USA Foundation 2020), but still realistic for most people on mid-to-high incomes - as evidenced by the growth of Giving What We Can (Giving What We Can, 2021). And many effective altruists settle for a smaller proportion than $10 \%$.

Another reason to go for a more moderate level of altruism is that the gains from increasing your level of altruism to extreme levels are not always that large. In other words, extreme altruism, if acquired, is not necessarily that impactful. This is clearest in the case where your primary path to impact is via direct work (e.g., for a political party or a charity). You usually cannot increase your impact that much by 
sacrificing more of your time. There are only so many hours in the week, meaning that the difference compared with a moderate altruist who already works full-time would not be huge.

If your primary path to impact is via donations, sacrificing more can make a greater difference. But as we shall see in the following sections, you can increase your impact even more in other ways. Suppose that you are a moderate altruist who donates $10 \%$ of your income to charity. If you increase that proportion to extreme altruism-levels, you could arguably increase your impact almost ten times (depending on what you earn). That may sound like a huge number, but actually, increasing the effectiveness of those donations makes a much bigger difference (cf. Caviola et al., 2021). Research suggests that global poverty-focused donors will increase their donations around a hundred times if they redirect them from a charity of average effectiveness to the most effective charity (Caviola et. al., 2020a, Ord, 2019, Jamison et al. 2006). And donors who focus on less effective causes can likely increase the effectiveness of their donations even more through switching to an effective global poverty charity. That means that increasing the effectiveness of your donations - through cultivating virtues such as moral expansiveness, effectiveness-focus, and truth-seeking - is typically more important than increasing the amount that you donate. And as we shall see, these virtues are also likely more acquirable. So given that people only have so much energy to spend on overcoming the different psychological obstacles to utilitarianism, it seems that they should those virtues.

\section{Moral expansiveness}

So far, we have looked at impartiality between ourselves and others. But another aspect of utilitarian impartiality is impartiality between different groups of other people. On the face of it, utilitarianism requires people to be impartial between all potential beneficiaries (cf. Kahane et al., 2018). According to this view, utilitarians should not even prioritize their own family members or close friends over strangers.

Call this "extreme impartiality". Just like extreme altruism, it is very demanding. And just as utilitarians should not in fact cultivate extreme altruism (when you factor in our psychological limitations), so they should not in fact cultivate extreme impartiality, in our view. They should analyze the different forms of impartiality - between compatriots and foreigners, current people and future people, humans and animals, family and strangers, and so on-and only cultivate the forms of impartiality that are sufficiently acquirable and impactful.

Let us start with the acquirability of impartiality between family members and strangers. Many philosophers have argued that such impartiality would in fact not be helpful, even though it may seem so at first glance (e.g., Sidgwick, 1907/1981, Pettit and Brennan, 1986, Jackson, 1991, de Lazari-Radek and Singer, 2013). We agree with that view. Just like other animals, humans have an innate drive to help their close kin, such as their children. Genes that make us partial in favor of people who partially share our genes were more likely to propagate themselves (Hamilton, 1964, Gardner et al., 2011). We have therefore evolved strong preferences for our kin. While these preferences are not completely immutable, it seems difficult to change them fundamentally. For instance, attempts at communal childrearing at Israeli kibbutzim have largely failed, as parents wanted to retain their special, partial, relationship with their children (Christakis, 2019). Our judgment is therefore that there are pretty strong limits to how mutable our preferences for our kin are. 
For that reason, it seems likely that attempts to become impartial between family members and strangers would fail, just as attempts to become impartial between oneself and others (extreme altruism) would fail. It could lead to distress and burnout. And it would most likely harm recruitment to a community that had that as a norm. It would also decrease the utilitarians' well-being, which in turn would have a direct negative effect from a utilitarian perspective (cf. Parfit, 1984, pp. 27-28). ${ }^{6}$

So it seems hard and costly to change our partial preferences for family members over strangers. The same is probably true of our partial preferences for close friends. Even though they are not family, we still have close bonds with them, and are unlikely to want to be impartial between them and strangers.

The situation is quite different, however, when it comes to other forms of partiality. For instance, we do not have an evolved disposition to be partial specifically for our compatriots over foreigners. We hardly could have, since there were no nation-states in the ancestral environment (Gellner, 1983). It is true that we have some inherited tribalistic tendencies, but they seem relatively mutable - certainly much more so than partiality in favor of our family. In fact, there are already many people who are not particularly nationalistic, especially among liberal groups in Western countries (World Value Survey, 2021). In Peter Singer's words, we have gradually expanded our circle of moral concern (Singer 1981/2011). So this form of partiality is likely easier to affect (though we admit that this may vary with cultural factors; see the introduction).

These considerations lead us to think that we should distinguish between two key forms of partiality. One the one hand, we have partiality for family and friends (exactly how far to extend this group can be discussed) over strangers. On the other hand, we have group membership-partiality: partiality for some large categories of beneficiaries - the vast majority of whom we have no personal relation withover other categories of beneficiaries. This includes partiality for compatriots over foreigners, current people over future people, and humans over animals. It seems much harder to overcome partiality for family and friends than to overcome group membership-partiality. Being impartial with respect to family and friends requires us to change all aspects of our lives completely: to stop treating our family and friends differently from any other person. Being impartial with respect to larger groups typically has much less far-reaching consequences (though again, this varies with cultural context). It does affect decisions such as what charity to donate to, what party to vote for, and potentially (depending on other factors) what job we choose. But it often leaves the private and personal side of our lives relatively unaffected. In line with that, outside of work many effective altruist utilitarians lead lives that in many ways are remarkably similar to those of most people in society.

In light of these considerations, we suggest that utilitarians cultivate the virtue of moral expansiveness (Crimston et al., 2016, 2018). They should continue expanding their circle of moral concern to include beneficiaries who are distant in terms of space (foreigners), time (future people), and biology (animals). They should not discriminate in favor of closer beneficiaries, except when they have a strong personal relationship with them. According to this view, utilitarians should permit themselves to be partial in favor of people within their personal sphere, which includes both yourself and your family and friends. But outside of that personal sphere, you should be impartial, and not discriminate against distant beneficiaries.

\footnotetext{
${ }^{6}$ We thank an anonymous reviewer for this point. We should say, however, that this effect may be relatively small compared with the negative effects of extreme partiality on utilitarians' impact on others, via, e.g., burnout -at least when their impact on others is large, as we have argued may often be the case.
} 
One reason that this is important is that you can have a much greater impact (as measured by utilitarian metrics) by helping distant beneficiaries than by helping beneficiaries that are close to us. For instance, our money tends to "go further overseas": donors in rich countries can do much more good by giving to the global poor, than by giving to poor people in their own countries (MacAskill, 2015; GiveWell). Likewise, because animals at factory farms are so neglected, donations to charities focusing on helping them can have an outsized impact (Animal Charity Evaluators, 2016). Lastly, some effective altruistsso-called longtermists - think that interventions that help the distant future are still much more effective (Greaves \& MacAskill, 2021). So not only is the virtue of moral expansiveness acquirable, but it is also impactful.

\section{Effectiveness-focus}

Partial feelings, both for ourselves and for those close to us, are powerful obstacles to utilitarianism. But it is not the only way in which feelings block people from acting on utilitarianism. Another problem is that people's feelings for others are not proportionate with the scale of their suffering (Bloom, 2017). Research has shown that we exhibit scope insensitivity: we are not much more motivated to help 200,000 individuals who suffer, than 20,000 individuals, or even 2,000 individuals (Desvouges et al., 1992). Our altruistic emotions did not evolve to help us maximize impact (Burum et al., 2020; Miller, 2000; Simmler and Hanson, 2017) and are not attuned to the large altruistic opportunities that you are presented with in the modern world (Lloyd et al., 2011, Cosmides and Tooby, 2006). Therefore, we do not necessarily get more motivated to help just because we could help more people.

People also have strong feelings for specific causes and charities, and choose to donate to them even when they know that that is less effective. In one study, participants were presented with the opportunity to support three different kinds of medical research which varied in terms of effectiveness. They were informed that it is most effective to support arthritis research, second most effective to support heart disease research, and least effective to support cancer research. Their inclinations to donate were the other way around, however: most supported cancer research, whereas arthritis research received the least support (Berman et al., 2018). This is a common phenomenon: people have "pet causes" which they insist on supporting, either because they have a personal connection to that cause, or because they are somehow more salient and striking. For instance, our studies show that many want to support disaster relief (a salient cause) even when informed that it is more effective to address recurring or permanent problems (Caviola et al. 2020b).

To overcome these biases, utilitarians should be effectiveness-focused..$^{7}$ They should cultivate the tendency to systematically choose the most effective ways of helping others, even when their natural inclination is to help in some other way. Note that we do not, however, suggest that they need to align their feelings with the impact of their interventions. It is not possible to feel a million times more for a million suffering people than for a single person (Yudkowsky, 2008). Instead, we mean that they should cultivate the habit of making their altruistic actions based on assessments of impact, rather than on intuitive reactions. And changing behavior in this regard seems much easier than changing feelings. While it is by no means trivial to be consistently focused on effectiveness, our judgment is that it is far easier than to become, e.g., fully selfless, or fully impartial in relation to one's family. For instance, many effective altruists arguably do live the virtue of effectiveness-focus.

\footnotetext{
${ }^{7}$ Richard Yetter Chappell (2019) has suggested a more general virtue which he calls "abstract benevolence" corresponding to both moral expansiveness and effectiveness-focus, but we found it useful to have two virtues here rather than one.
} 
Effectiveness-focus is also highly impactful, since the biases that we have discussed in this section reduce people's impact enormously. As we saw, our studies show that the most effective charities are at least one hundred times more effective than the average charity (Caviola et al. 2020a). That means that it is crucial to choose the most effective charities. But because of scope insensitivity and other biases, donors often choose charities with little regard for impact. On average, they donate to the average charity (otherwise those charities would not continue to operate). So these biases mean that the average donor loses at least $99 \%$ of their potential impact. Hence, utilitarians can vastly increase their impact through overcoming these biases, and by being focused on effectiveness.

\section{Truth-seeking}

As the preceding sections have shown, people are often disinclined to choose the most effective ways of helping others, even when they are presented to them. Moral expansiveness and effectiveness-focus would help utilitarians to overcome that obstacle. But there is another problem that those virtues do not solve - namely to identify which ways of helping others are most effective. More often than not, effective opportunities are not lined up in front of the utilitarian do-gooder. Instead, they have to find them themselves. Here, new obstacles to utilitarianism present themselves.

The world is complex, and it is difficult to find the most effective altruistic interventions. This is particularly so since many of the interventions that are likely to be most effective aim to help distant beneficiaries. It is typically harder to estimate the impact of interventions that help distant beneficiaries than the impact of interventions that help people nearby. For instance, it is normally harder to estimate the impact of interventions helping people in distant poor countries, than the impact of interventions in the United States and Western Europe, where governments collect much more data about their citizens. And it is especially hard to estimate the impact of longtermist interventions. Assessing the effects of our current actions on the long-term future - hundreds, thousands, or even millions of years from nowposes formidable epistemic challenges (Tarsney, 2019).

To identify the most effective altruistic interventions, utilitarians therefore must have an attitude of honest and humble truth-seeking (cf. Schmidt, 2017). But as a wealth of psychological research has shown, this is not our default epistemic attitude. Instead, human reasoning is plagued by a range of biases. Let us here just cover a few particularly important examples.

One of the most salient epistemic problems is our tendency to engage in motivated reasoning (Kunda, 1992). Instead of impartially evaluating the evidence, we tend to be biased in favor of views that we find politically convenient, or which we like for other reasons (Kahan, 2015). Likewise, there is the ubiquitous confirmation bias: we selectively seek out evidence that supports our views, while neglecting evidence that would falsify them (Oswald and Grosjean, 2004). Relatedly, we tend to be overconfident - to overestimate our own expertise relative to others' (Hoffrage, 2004). As a result, we are often insufficiently inclined to defer to our epistemic peers or superiors. For instance, donors often have little knowledge of what the most effective charities are (Caviola et al. 2020b) - but instead of seeking out experts, who do know, they go with their own guesses. This obviously tends to reduce the effectiveness of their donations.

We are also, to varying degrees, cognitive misers - we do not seek out evidence to the extent that we should, and we often rely on intuition when it would be more appropriate to engage in more effortful 
deliberative reasoning (Stanovich et al., 2016). Partly for that reason, many have not acquired the "mindware" - the concepts and the reasoning tools - that they need to estimate the relative value of different ways of doing good (ibid.). For instance, many people are unfamiliar with the concept of expected value, and their grasp of probabilistic reasoning is often shallow (Caviola et al. 2020b, Baron, 2000, Pinker, 2021).

Because of these biases and other shortcomings, utilitarians need to cultivate the virtue of truthseeking. ${ }^{8}$ Instead of being partial in favor of views that they currently hold, or which they like for political or other reasons, they should try to be epistemically impartial, as far as possible. They should cultivate open-mindedness (Stanovich \& West, 1997, Baron, 2018) about new and radical ideas. Instead of being overconfident, they should be humble and willing to defer to experts. And they should be rigorous and epistemically conscientious - they should be willing to do the hard work of identifying and scrutinizing relevant evidence, instead of going with intuition. Relatedly, they should be willing to learn the scientific mindware or thinking tools that are necessary to compare altruistic interventions.

It is of course not possible to completely eradicate all these biases. We cannot reach epistemic perfection. But we can improve. We have already improved a lot over the course of history. In particular, the Scientific Revolution was tantamount to spectacular epistemic progress, with stunning real-world consequences (Mokyr, 2016). And there is no reason to think that we cannot continue to improve. Within the effective altruism community, truth-seeking is celebrated as a key virtue or norm: the community even describes itself in terms of using "high-quality evidence and careful reasoning to work out how to help others as much as possible" (EffectiveAltruism.org, 2020). That arguably incentivizes members to overcome their biases, to be open to changing their mind, and to use relevant mindware: all of which are conducive to a better epistemic mindset.

So the virtue of truth-seeking is arguably relatively acquirable. But it is also very impactful. As we have seen, the differences in effectiveness between different interventions are huge. And that makes it extremely important to actively search for the very best interventions.

Utilitarianism does not assign any intrinsic value to truth-seeking or truth-telling, of course. Rather, it only has instrumental value for the utilitarian. That may lead people to think that utilitarianism assigns lower value to the truth than common sense morality does. But in fact, in our view it is the other way around. Common sense morality arguably does not assign a very high value to truth-seeking and intellectual honesty. It even says that in some cases you ought to have epistemically unjustified beliefs - e.g., that you should believe that a friend accused of crime is innocent, even though the evidence suggests otherwise (Cusimano and Lombrozo, 2021). Similarly, most people likely see no problem with convincing yourselfthat your favorite ways of doing good are effective, even when that is not so. And common sense morality certainly does not require you to do careful research on what ways of doing good are most effective.

By contrast, utilitarianism entails (in the current cultural and socio-economic context) that it is of great moral importance to overcome your epistemic biases and find out what ways of doing good are actually most effective. In that sense, real-world utilitarianism is actually quite epistemically demanding. Most discussions about utilitarianism and demandingness focus on demands on our material resources, but the epistemic demands are arguably more important when you apply utilitarianism in the real world.

\footnotetext{
${ }^{8}$ Or "the scout mindset", as the effective altruist Julia Galef (2021) calls it.
} 
And for most people, it may be less draining to try to improve epistemically, than to give away large material resources.

\section{Collaborativeness}

So far, we have focused on psychological obstacles that prevent individual utilitarians from maximizing their personal impact. But utilitarians also need to coordinate and collaborate with others in order to maximize their collective impact. Let us now look at the psychological obstacles that prevent such coordination and collaboration, and the virtue that we need to overcome them: the virtue of collaborativeness. $^{9}$

As Adam Smith (1776/1976) noted, economic progress to a large extent occurs thanks to deepening coordination and collaboration: to trade and to specialization. People are much more effective when they divide labor between them, specialize on specific tasks, and trade their surplus goods and services for those that they lack. Whereas he was talking about self-interested pursuits, something similar is true of altruistically motivated pursuits. Utilitarians can do much more good if they form a community where they divide tasks between themselves, where they help each other (either with or without remuneration), share information, and so on. This has been recognized by many utilitarians, which is part of why they have chosen to be part of the effective altruism community.

The effective altruism community is intensely collaborative. Some members focus on "earning to give" - to earn as much money as possible, in order to fund charities (Todd, 2014, Singer, 2015). Other members work directly for some of those charities. Still others provide free career advice to help members choose between these options (80,000 Hours, 2021). And the effective altruism community is also collaborative in many other ways. It has in a short period of time been able to steer hundreds of millions of dollars toward effective charities (Open Philanthropy, 2021). It seems unlikely that they would have been able to do that if they had not collaborated to such an extent.

Another reason for forming a community is that it likely helps to develop and maintain the virtues that we discuss in this chapter. Within the effective altruism community, these virtues are effectively norms. You are celebrated for having these virtues by your peers. That obviously makes it easier to acquire them and to live them. And since those virtues increase people's impact, having a community that helps people living those virtues also increases impact.

But utilitarians should just not collaborate and cooperate with other utilitarians, but also with people who have different moral views. Or at least, they should be willing to engage in coordination and compromises with them. ${ }^{10}$ Toby Ord, one of the founders of the effective altruism community, has pioneered the concept of moral trade (Ord, 2015). We trade all the time to satisfy our self-interested preferences: I give you my service in return for your goods (usually mediated by money). As Ord points out, we can do the same regarding moral preferences. Suppose that Alice finds veganism much more morally important than Bob, whereas Bob feels more strongly about global poverty. Then Alice and Bob can satisfy their moral preferences better if Alice promises to give to global poverty charities provided that Bob reciprocates through becoming a vegan.

\footnotetext{
9 "To collaborate" can both mean to work jointly on a shared project and to cooperate with a foreign occupying power. Obviously we are using the word in the first sense, not the second sense.

${ }^{10}$ Depending on the nature of those view. The case for cooperating with people who hold clearly objectionable views is weaker.
} 
In the real world, opportunities to engage in explicit moral trade may not be so common. But there are many ways in which it can make a difference to have norms of moral compromise and cooperation. For instance, to engage in civil discourse even with people whom you morally disagree with. Or to avoid saying and doing things that are objectionable from the point of view of other reasonable moral perspectives, unless it is strictly necessary. Anecdotally, it seems that the effective altruism community is morally cooperative in this way, that that reduces conflict within the community, and that that in turn increases its impact.

But even though coordination and collaboration are likely very valuable, people do not always engage in it naturally. Notably, throughout history most utilitarians have not been part of intensely collaborative communities like the effective altruism community. Instead, they have usually acted more independently. ${ }^{11}$

Why is coordination and collaboration not more common? One reason is probably that people have a natural tendency to want to pursue their own projects, according to their own wishes. But since a small number of projects tend to be much more effective than the rest, you can usually increase your impact a lot through joining one of them.

People are faced with the same problem on the regular labor market, where they are working for their own ends. It can be more fun and rewarding to pursue your own projects or start your own company than to work for someone else. Some do that, but most join more effective companies run by others. The reason is, of course, that such jobs tend to have better pay and greater job security. So there is a strong incentive to overcome your aversion to joining other people's projects.

But when people are working for altruistic ends, the incentives are not quite as strong. Doing good in an independent fashion might decrease your impact, but typically does not drastically reduce your standard of living (at least not if you pursue it as an independent project on the side of your normal job) the way working as a less successful entrepreneur might. That means that there is less incentive to engage in intense collaboration on the altruistic side of things.

People may also simply neglect the importance of altruistic collaboration, and fail to see how much it increases their impact. When it comes to for-profit companies, effectiveness tends to be very salient. We can see how much profit companies make, and how much they pay their employees. It is typically much less salient how effective altruistic projects are. That may cause people to underestimate how effective the most effective altruistic projects are (cf. Caviola et al., 2020a), and thereby cause them to underestimate the impact of joining one of those projects.

When it comes to moral trade and other forms of cooperation with our moral opponents, there is another factor. People often feel outraged or disgusted over other people's moral views, and therefore refuse to cooperate or even compromise with them (Haidt, 2012). Having such attitudes may be a signal to your ingroup of your commitment: that you will not defect. While understandable, such attitudes are often unhelpful, and can lead to protracted and costly fights between decent people who happen to disagree on some salient moral issues.

\footnotetext{
${ }^{11}$ The 19th century "Philosophic Radicals" in Britain was to some extent an exception. See (Thomas, 1979).
} 
To overcome these obstacles, utilitarians should cultivate the virtue of collaborativeness. We have already seen that it is impactful - that being collaborative substantially increases impact. But it is also arguably acquirable. The effective altruist community is already reasonably collaborative, demonstrating that it is indeed possible to live in accordance with the virtue of collaborativeness.

\section{Determination}

One of the most salient features of human psychology is that we do not always do what we on some level want to do. We decide to lose weight, but keep eating too much. We plan to save, but continue being profligate. We endorse a stringent moral philosophy in theory, but go on acting as we did before in practice.

So actually applying one's moral views is harder than it may seem. Many suffer from an intentionbehavior gap - they intend to take action, but fail to actually do so (Sheeran and Webb, 2016). Instead of acting on utilitarian principles, they fall back on standard habits. They pursue low-impact causes, or do not take much altruistic action at all.

One reason is simple inertia. Another is availability bias - the tendency to do what is most prominent and talked about (Schwarz and Vaughn, 2002). A third is a satisficing attitude (Misuraca, 2015). Instead of considering all the possible interventions that they could pursue, and choosing the one that is most effective (maximizing), many do a more limited search and settle for an intervention that is "good enough".

To overcome these obstacles, utilitarians should cultivate the virtue of determination. That means to have an active mind - to refuse to drift into pursuing sub-optimal interventions because of inertia, prominence, or a satisficing attitude. And it means to be as hard-working as necessary, without risking getting burnt out. Analogously with truth-seeking, real-world utilitarianism arguably puts a greater moral weight on these qualities than common sense morality does.

The virtue of determination also entails staying motivated over the long-term. Having a utilitarian impact is a marathon, not a sprint. Suppose that you become a utilitarian as a twenty-year old student, and that you decide to dedicate your career to utilitarian causes. Most likely, the vast majority of your impact will lie decades ahead, when you have reached more senior positions. This means that it is very important for utilitarians to cultivate perseverance, determination, and long-term motivation.

In particular, utilitarians must approach the issues that make the largest difference with determination and poise. There are many morally coded issues that only make a small difference, like saving on electricity by turning off your TV when you do not use it (MacAskill, 2015). It is not a big problem to fail to be deliberate about them. Instead, utilitarians should save their energy for the big decisions in life: what cause to prioritize, what your next job should be, and what charity you should donate to.

Because of our natural tendency not to follow through with idealistic plans, the virtue of determination is likely highly impactful. But it also seems relatively acquirable. Again, it helps to have community norms. The effective altruism community celebrates determination, just like it celebrates truth-seeking: cf. the slogan "figure out how to do the most good, and then do it" (Cotra, 2017). These norms seem to help utilitarian effective altruists. Utilitarians outside of the effective altruist community risk drifting into pursuing lower-impact causes that are the default in their social circles, but in effective altruist 
circles, the default is to pursue a cause that is highly effective. That arguably aids utilitarian effective altruists to live in accordance with the virtue of determination.

\section{Putting our suggested utilitarian virtues in context}

We suggest that to apply utilitarianism in the real world, utilitarians should cultivate the virtues of moderate altruism, moral expansiveness, effectiveness-focus, truth-seeking, collaborativeness, and determination. Let us now put our suggestion in perspective. How do these virtues compare with how utilitarianism may appear at first glance? With common sense morality? And with other theories of utilitarian virtues?

Much of the philosophical and psychological debate on utilitarianism focuses mainly on counterintuitive edge cases. Should you push one person in front of a trolley in order to kill five (Foot, 1967, Greene et al., 2001, Greene, 2013)? Should you sacrifice your own life to save a greater number (Sachdeva et al., 2015)? These debates might make it seem as if such edge cases are very important for those that try to act on utilitarianism in the real world.

But in fact, they are not. The edge cases are useful as tests of our intuitions about whether utilitarianism is our best or most correct moral theory (Greene, 2013). But when we move from the world of abstract thought-experiments to the real world, those kinds of situations just do not appear very often. Instead, there are other decisions which are much more important: decisions like what charity to donate to and what career to choose. And for these decisions, utilitarians rather need the six virtues that we have discussed here.

Moreover, the real-world situations that are most similar to, e.g., the trolley problem tend to be different from it in crucial ways. In the trolley problem, you are asked whether you would do harm for the greater good ("instrumental harm"). There are, of course, situations where we could conceivably do good by causing instrumental harm - by lying, stealing, or breaking other common sense-norms (e.g., we could steal money and give to the poor). But in the real world, such norm-breaking often comes with large costs. It would lead to people taking precautions to safeguard against these kinds of harms, which would be costly for society. And research has shown that people who engage in instrumental harm for the greater good suffer reputational costs (Everett et al. 2018). If utilitarians became known for breaking rules and for being generally untrustworthy, their ability to do good could be seriously impaired. In light of such considerations, many have argued that it is better for utilitarians to stick to common sense norms, even if it naively may seem as if you could do more good by breaking them (e.g., Mill, 1838, Sidgwick, 1907/1981, Crisp, 1992, Hooker, 2002, Ord, 2009). It is thus probably wise for utilitarians to adopt ordinary virtues like honesty, trustworthiness, and kindness. That will improve their reputation, and will also facilitate collaboration between utilitarians (Schubert et al. 2017).

As we have seen, utilitarianism also converges considerably with common sense morality concerning altruism and impartiality. They should not feel that they have to donate to the point of marginal utility. And they should not force themselves to be impartial between their family and strangers.

Some generalize these insights and argue that utilitarianism converges with common sense morality more or less across the board (Mill, 1861/1992, Railton, 1984). This view says that utilitarianism seems like a radical departure from our pretheoretical ethical world-view at first glance, but if you do the analysis properly, you realize that it is not so. 
But while it is true that utilitarianism has more in common with common sense morality than one might naively think, there is something that this argument misses. Utilitarians can massively increase their impact through cultivating some key virtues that are not usually emphasized by common sense morality. Some charities are extraordinarily effective compared with the average charity, and some jobs are much higher-impact than other jobs. To take these opportunities, utilitarians need to acquire the virtues of moral expansiveness and effectiveness-focus. They need to be truth-seeking, so that they are able to find these opportunities. They need to collaborate with others to an unusually high degree. And they need to be determined, so that they actually act on the best opportunities.

So we suggest that in order to be effective in the real world, utilitarians should stake out a middle way. They should by and large adopt the standard common sense virtues, pace what a naive analysis would have it. But in addition to them, they should also adopt six virtues that go beyond the common sense virtues. So while a utilitarian life is pretty normal in some ways, it is very different in others.

Some of our suggested virtues tend to be associated with utilitarianism. That is especially true of altruism (though, as stated, some think it should be extreme rather than moderate) and moral expansiveness. But others do not have a salient link to utilitarianism, and do not tend to be associated with it. They include, in particular, truth-seeking, collaborativeness, and determination. None of these virtues are as it were conceptually tied to utilitarianism, but empirically, it turns out that they are very important in order to maximize utilitarian impact in the real world. Or that is our hypothesis.

Lastly, let us again emphasize that we take the effective altruism community and its insights as the starting point of our analysis of utilitarian virtue. In this we differ from most thinking of utilitarian virtue, much of which focuses on what virtues and norms there should be in a society run on utilitarian principles (cf. Goodin, 1995). While there is merit to such perspectives as well, our project is different: we want to figure out what virtues utilitarians should acquire here and now in order to maximize their impact in the real world - given that there are not many utilitarians, and given that it is unlikely that society will be run on utilitarian principles any time soon. Therefore, it is natural to draw on the lessons from the effective altruism community - since utilitarians in the effective altruism community arguably have been more systematic than other utilitarians about maximizing their impact in the real world.

\section{Conclusions}

We have suggested six virtues that utilitarians should cultivate to overcome psychological obstacles to utilitarianism: moderate altruism, moral expansiveness, effectiveness-focus, truth-seeking, collaborativeness, and determination. To reiterate, this list is tentative, and should be seen more as a starting point for further research than as a well-consolidated set of findings. It is plausible that some of our suggested virtues should be refined, and that we should add further virtues to the list. We hope that it should inspire a debate among philosophers and psychologists about what virtues utilitarians should prioritize the most.

\section{References}

80,000 hours. Accessed 15 May 2021. https://80000hours.org/speak-with-us/ 
Animal Charity Evaluators, "Why Farmed Animals" (2016), accessed July 16, 2020, https://animalcharityevaluators.org/donation-advice/why-farmed-animals/.

Baron, Jonathan. "Nonconsequentialist decisions." Behavioral and Brain Sciences 17, no. 1 (1994): 110.

Baron, Jonathan. Thinking and deciding. Cambridge University Press, 2000.

Baron, Jonathan. "Social norms for citizenship." Social Research: An International Quarterly 85.1 (2018): 229-253.

Bazerman, Max. Better, not perfect: a realist's guide to maximum sustainable goodness. Harper Business, 2020.

Berman, Jonathan Z., Alixandra Barasch, Emma E. Levine, and Deborah A. Small. "Impediments to effective altruism: The role of subjective preferences in charitable giving." Psychological science 29, no. 5 (2018): 834-844.

Bloom, P. (2017). Against empathy: The case for rational compassion. Random House.

Bradley, Ben. "Contemporary Consequentialist Theories of Virtue." In The Oxford Handbook of Virtue. 2018.

Burum, Bethany, Martin A. Nowak, and Moshe Hoffman. "An evolutionary explanation for ineffective altruism." Nature Human Behaviour (2020): 1-13.

Caviola, Lucius, Stefan Schubert, Elliot Teperman, David Moss, Spencer Greenberg, and N. Faber. "Donors vastly underestimate differences in charities' effectiveness." Judgment and Decision Making 15, no. 4 (2020a), 509-516.

Caviola, Lucius, Stefan Schubert, and Jason Nemirow. "The many obstacles to effective giving." Judgment and Decision Making 15, no. 2 (2020b), 159-172.

Caviola, Lucius, Stefan Schubert, and Joshua D. Greene. "The Psychology of (In) Effective Altruism." Trends in Cognitive Sciences (2021).

Chappell, Richard Yetter, "Overriding Virtue". In Effective Altruism: Philosophical Issues, edited by Hilary Greaves and Theron Pummer, pp. 218-226. Oxford University Press, 2019.

Christakis, Nicholas A. Blueprint: The evolutionary origins of a good society. Hachette UK, 2019.

Cohen, Yishai. "Actualism and Possibilism in Ethics", in Stanford Encyclopedia of Philosophy, edited by Edward N. Zalta. https://plato.stanford.edu/entries/actualism-possibilism-ethics/

Cosmides, Leda, and John Tooby. Evolutionary psychology, moral heuristics, and the law. Dahlem University Press, 2006. 
Cotra, Ajeya. "Introduction to Effective Altruism". April 14, 2017. https://forum.effectivealtruism.org/s/YCa8BRQoxKbmf5CJb/p/5EqJozsDdHcF7dpPL

Crimston, Daniel, Paul G. Bain, Matthew J. Hornsey, and Brock Bastian. "Moral expansiveness: Examining variability in the extension of the moral world." Journal of Personality and Social Psychology 111, no. 4 (2016): 636-653.

Crimston, Daniel, Matthew J. Hornsey, Paul G. Bain, and Brock Bastian. "Toward a psychology of moral expansiveness." Current Directions in Psychological Science 27, no. 1 (2018): 14-19.

Crisp, Roger. "Utilitarianism and the Life of Virtue." The Philosophical Quarterly 42, no. 167 (1992): 139-160.

Crisp, Roger. "Hume on Virtue, Utility and Morality". In Gardiner, Stephen M., ed. Virtue ethics, old and new. Cornell University Press, 2018.

Crockett, Molly J., and Patricia L. Lockwood. "Extraordinary altruism and transcending the self." Trends in cognitive sciences 22, no. 12 (2018): 1071-1073.

Cusimano, Corey, and Tania Lombrozo. "Morality justifies motivated reasoning in the folk ethics of belief." Cognition (2021): 104513.

Desvouges, William F., Reed Johnson, Richard Dunford, Kevin Boyle, Sarah Hudson, Nicole K. Wilson. "Measuring Non-Use Damages Using Contingent Valuation: An Experimental Evaluation of Accuracy" (PDF). Research Triangle Institute Monograph. 92-1 (1992). doi:10.3768/rtipress.2009.bk.0001.1009.

Driver, Julia. Uneasy Virtue, New York: Cambridge University Press. 2001

Everett, Jim AC, Nadira S. Faber, Julian Savulescu, and Molly J. Crockett. "The costs of being consequentialist: Social inference from instrumental harm and impartial beneficence." Journal of experimental social psychology 79 (2018): 200-216.

Effectivealtruism.org. "Introduction to Effective Altruism", March 12020. https://www.effectivealtruism.org/articles/introduction-to-effective-altruism/

Foot, Philippa. "The problem of abortion and the doctrine of the double effect." Oxford Review 5 (1967): 5-15.

Galef, Julia. The Scout Mindset: Why Some People See Things Clearly and Others Don't. Penguin, 2021.

Gardner, Andy, Stuart A. West, and Geoff Wild. "The genetical theory of kin selection." Journal of evolutionary biology 24, no. 5 (2011): 1020-1043.

Gellner, Ernest. Nations and Nationalism. Blackwell, 1983. 
GiveWell. "Your Dollar Goes Further Overseas". https://www.givewell.org/giving101/Your-dollargoes-further-overseas Accessed 21 May, 2021.

Giving USA Foundation. Giving USA 2020: Charitable giving showed solid growth, climbing to $\$ 449.64$ billion in 2019, one of the highest years for giving on record. Giving USA Report.

Giving What We Can, about us. https://www.givingwhatwecan.org/about-us/ Accessed 16 July, 2021.

Goodin, Robert E. Utilitarianism as a public philosophy. Cambridge University Press, 1995.

Greaves, Hilary, and William MacAskill. "The case for strong longtermism." Global Priorities Institute working paper no 5, 2021.

Greene, Joshua David. Moral tribes: Emotion, reason, and the gap between us and them. Penguin, 2013.

Greene, Joshua D., R. Brian Sommerville, Leigh E. Nystrom, John M. Darley, and Jonathan D. Cohen. "An fMRI investigation of emotional engagement in moral judgment." Science 293, no. 5537 (2001): 2105-2108.

Haidt, Jonathan. The righteous mind: Why good people are divided by politics and religion. Vintage, 2012.

Hamilton, William D. "The genetical evolution of social behaviour. II." Journal of theoretical biology 7, no. 1 (1964): 17-52.

Hoffrage, Ulrich. "Overconfidence." Cognitive illusions: A handbook on fallacies and biases in thinking, judgement and memory (2004).

Hooker, Brad. Ideal code, real world: A rule-consequentialist theory of morality. Oxford University Press, 2002.

Jackson Frank "Decision-Theoretic Consequentialism and the Nearest and Dearest Objection," Ethics (1991), no 101(3): 461-482. doi:10.1086/293312

Jamison, Dean et al. Disease control priorities in developing countries, The World Bank. (2006).

Kagan, Shelley. The Limits of Morality. New York: Oxford University Press (1989).

Kahan, Dan M. "The politically motivated reasoning paradigm, part 1: What politically motivated reasoning is and how to measure it." Emerging trends in the social and behavioral sciences: An interdisciplinary, searchable, and linkable resource (2015): 1-16.

Kahane, Guy, Jim AC Everett, Brian D. Earp, Lucius Caviola, Nadira S. Faber, Molly J. Crockett, and Julian Savulescu. "Beyond sacrificial harm: A two-dimensional model of utilitarian psychology." Psychological Review 125, no. 2 (2018): 131.

Kaplow, Louis, and Steven Shavell. "Human nature and the best consequentialist moral system." Available at SSRN 304384 (2002). 
Kunda, Ziva. "The case for motivated reasoning." Psychological bulletin 108, no. 3 (1990): 480.

de Lazari-Radek, Katarina, and Peter Singer. "How much more demanding is utilitarianism than common sense morality?" Revue International de Philosophy, 2013, no. 67 (4): pp. 427-438.

de Lazari-Radek, Katarzyna, and Peter Singer. Utilitarianism: A very short introduction. Oxford University Press, 2017.

Lloyd, Elisabeth, David Sloan Wilson, and Elliott Sober. "Evolutionary mismatch and what to do about it: A basic tutorial." Evolutionary Applications (2011): 2-4.

MacAskill, William. Doing good better: Effective altruism and a radical new way to make a difference. Guardian Faber Publishing, 2015.

Mill, John Stuart (1838), "Bentham", in John M. Robson (ed.) Collected works (vol. X), Toronto: Toronto University Press: pp. 75-116.

Mill, John Stuart. Utilitarianism, In On Liberty and Utilitarianism, Knopf: Everyman's Library, Volume 81. 1861/1992.

Miller, Geoffrey. The mating mind: How sexual choice shaped the evolution of human nature. Heinemann, 2000.

Misuraca, Raffaella, Palmira Faraci, Amelia Gangemi, Floriana A. Carmeci, and Silvana Miceli. "The Decision Making Tendency Inventory: A new measure to assess maximizing, satisficing, and minimizing." Personality and Individual Differences 85 (2015): 111-116.

Mokyr, Joel. A culture of growth. Princeton University Press, 2016.

Ord, Toby. "The moral imperative toward cost-effectiveness in global health." In Effective Altruism: Philosophical Issues, edited by Hilary Greaves and Theron Pummer, pp. 29-36. Oxford University Press, 2019.

Ord, Toby. "Beyond Action: Applying consequentialism to decision making and motivation", 2009. (D. Phil. dissertation, University of Oxford.)

Ord, Toby. "Moral trade." Ethics 126, no. 1 (2015): 118-138.

Open Philanthropy Project, Grants Database, 2021. Accessed via https://www.openphilanthropy.org/giving/grants, May 17, 2021

Oswald, Margit E., and Stefan Grosjean. "Confirmation bias." Cognitive illusions: A handbook on fallacies and biases in thinking, judgement and memory 79 (2004).

Parfit, Derek. (1984). Reasons and persons. Oxford: Oxford University Press.

Pettit, Philip. "The consequentialist perspective", in Three Methods of Ethics, Blackwell, 1997. 
Pettit, Philip, and Geoffrey Brennan. "Restrictive Consequentialism", Australasian Journal of Philosophy, (1986), no 64(4): 438-55.

Pinker, Steven. Rationality: What It Is, Why It Seems Scare, Why It Matters. Allen Lane (2021).

Railton, Peter. "Alienation, Consequentialism, and the Demands of Morality", Philosophy and Public Affairs 13 (1984): 134-171.

Rethink Priorities. EA Survey 2019: Community Demographics and Characteristics. December 5, 2019. https://www.rethinkpriorities.org/blog/2019/12/5/ea-survey-2019-series-community-demographicsamp-characteristics

Sachdeva, Sonya, Rumen Iliev, Hamed Ekhtiari, and Morteza Dehghani. "The role of self-sacrifice in moral dilemmas." PloS one 10, no. 6 (2015): e0127409.

Scheffler, S., 1994. The rejection of consequentialism: A philosophical investigation of the considerations underlying rival moral conceptions. Oxford University Press.

Schmidt, Andreas. T. "Being Good by Doing Good: Goodness and the Evaluation of Persons." Utilitas 29, no. 1 (2017): 3.

Schubert, Stefan, Ben Garfinkel, and Owen Cotton-Barratt. Considering Considerateness: Why communities of do-gooders should be exceptionally considerate. Effectivealtruism.org, June 1, 2017. https://www.effectivealtruism.org/articles/considering-considerateness-why-communities-of-dogooders-should-be/

Schwarz, Norbert, and Leigh Ann Vaughn. "The Availability Heuristic Revisited: Ease of Recall and Content of Recall as Distinct Sources of Information." Chapter in Heuristics and Biases: The Psychology of Intuitive Judgment, edited by Thomas Gilovich, Dale Griffin, and Daniel Kahneman, 103-19. Cambridge: Cambridge University Press, 2002. doi:10.1017/CBO9780511808098.007.

Sheeran, Paschal, and Thomas L. Webb. "The intention-behavior gap." Social and personality psychology compass 10, no. 9 (2016): 503-518.

Sidgwick, Henry. The Method of Ethics, 7th edition. Indianapolis: Hackett (1907/1981).

Simmler, Kevin, and Robin Hanson. The elephant in the brain: Hidden motives in everyday life. Oxford University Press, 2017.

Singer, Peter. "Famine, affluence, and morality." Philosophy \& public affairs (1972): 229-243.

Singer, Peter. The expanding circle: Ethics, evolution, and moral progress. Princeton University Press, $1981 / 2011$.

Singer, Peter. The most good you can do: How effective altruism is changing ideas about living ethically. Yale University Press, 2015. 
Smith, Adam. An Inquiry into the Nature and Causes of the Wealth of Nations. Edited by R.H. Campbell, A.S. Skinner, and W. B. Todd (eds.), Oxford: Oxford University Press, (1776/1976).

Stanovich, Keith E., Richard F. West, and Maggie E. Toplak. The rationality quotient: Toward a test of rational thinking. MIT press, 2016.

Stanovich, Keith E., and Richard F. West. "Reasoning independently of prior belief and individual differences in actively open-minded thinking." Journal of Educational Psychology 89, no. 2 (1997): 342 .

Tarsney, Christian. "The epistemic challenge to longtermism." (2019). Global Priorities Institute working paper no 10, 2019.

Thomas, William. The Philosophic Radicals: Nine Studies in Theory and Practice. Oxford: Clarendon Press.

Todd, Benjamin. "Why and how to earn to give". 80,000 Hours blog, 2014. https://80000hours.org/articles/earning-to-give/.

Unger, Peter. Living High and Letting Die. New York: Oxford University Press (1996).

World Value Survey Association, The 2020 World Cultural Map, 4 February 2021, https://www.worldvaluessurvey.org/WVSNewsShow.jsp?ID=428

Yudkowsky, Eliezer. "Cognitive biases potentially affecting judgment of global risks." In Global catastrophic risks, edited by Nick Bostrom and Milan M. Ćirković, (2008), pp 91-119. New York: Oxford University Press. 